\title{
APRESENTAÇÃO NÚMERO ESPECIAL DISSIDÊNCIAS DE GÊNERO \\ E SEXUALIDADE(S) EM CONTEXTOS INTERIORANOS E/OU \\ RURAIS: CRUZANDO TEMAS, PROBLEMAS E PERSPECTIVAS \\ CONTEMPORÂNEAS
}

\section{PRESENTATION SPECIAL NUMBER GENDER AND SEXUALITY (S) DISSIDENCES IN INTERIOR AND / OR RURAL CONTEXTS: CROSSING CONTEMPORARY TOPICS, PROBLEMS AND PERSPECTIVES}

\author{
Esmael Alves de Oliveira ${ }^{1}$ \\ Letícia Carolina Pereira do Nascimento ${ }^{2}$ \\ Lorena Lima de Moraes $^{3}$ \\ Marcio Caetano ${ }^{4}$
}

O presente dossiê temático é resultado de trocas e diálogos acadêmicos e afetivos estabelecidos em diferentes momentos entre nós, que vivemos em quatro contextos interioranos desse país de dimensões continentais. Como docentes de Universidades Federais localizadas nas regiões Nordeste (UFPI, UFRPE), Centro Oeste (UFGD) e Sul (UFPel), portanto, fora dos eixos metropolitanos das capitais, inquietamo-nos com as condições de invisibilidade de

\footnotetext{
${ }^{1}$ Atualmente é Professor Adjunto, em regime de dedicação exclusiva, do curso de Ciências Sociais, do Programa de Pós-Graduação em Antropologia (PPGAnt) da Faculdade de Ciências Humanas da Universidade Federal da Grande Dourados (FCH/UFGD) e do Programa de Pós-Graduação em Antropologia Social da Universidade Federal de Mato Grosso do Sul (PPGAS/UFMS). Doutorado em Antropologia Social pela Universidade Federal de Santa Catarina - PPGAS/UFSC (2014). e-mail: esmael_oliveira@live.com

2 Atualmente é Professora Assistente do curso de Pedagogia da UFPI/Campus Amílcar Ferreira Sobral. Doutoranda em Educação pela Universidade Federal do Piauí (UFPI/PPGEd). e-mail: llorenamoraes@gmail.com

${ }^{3}$ Atualmente é professora adjunta da Universidade Federal Rural de Pernambuco - Unidade Acadêmica de Serra Talhada. Doutorado em Ciências Sociais pela Universidade do Estado do Rio de Janeiro. e-mail: lorena.moraes@ufrpe.br

${ }^{4}$ Atualmente é Professor na Universidade Federal de Pelotas (UFPEL). Pós-doutor em Currículo e Narrativas Audiovisuais, com apoio do PNPD-CAPES, no Programa de Pós-Graduação em Educação da Universidade do Estado do Rio de Janeiro (UERJ). Doutorado em educação pela Universidade Federal Fluminense (UFF). e-mail: mrvcaetano@gmail.com
} 
trabalhos, investigações e reflexões produzidas e conduzidas por inúmeros pesquisadores e pesquisadoras das mais diversas Instituições de Ensino Superior no interior desse Brasil profundo. Embora essa constatação não se refira a todos os campos de pesquisa, tal invisibilidade é patente quando se trata das discussões acadêmicas em torno das temáticas de gênero e sexualidades.

Nesse sentido, este dossiê reuniu estudos e pesquisas sobre sexualidades dissidentes e as múltiplas expressões de gênero em contextos pouco visibilizados, tais como: cidades de pequeno e médio porte e/ou contextos rurais. $\mathrm{O}$ intuito foi discutir e refletir sobre as variadas formas de viver as identidades de gênero, práticas sexuais dissidentes, negociações e formas de resistência em contextos fora dos grandes centros urbanos.

Constatou-se que, embora o campo dos estudos de gênero no Brasil esteja em constante expansão, quando se trata de articulá-los a contextos interioranos e/ou rurais, há uma escassez de reflexões - e, quando estas existem, têm-se voltado principalmente para as questões do trabalho, família, participação política, formas de subsistência etc., promovendo a perpetuação de um silêncio sobre as vivências que se distanciam das expectativas sexuais e de gênero que são apoiadas na heteronormatividade.

Em artigo publicado em 2015 na revista Aceno (periódico vinculado à UFMT), os pesquisadores Fabiano Gontijo e Igor Erick (ambos da UFPA) apontaram que "pouco - ou praticamente nada - foi versado sobre as experiências desviantes no universo rural, em contextos interioranos ou em situações etnicamente diferenciadas" (GONTIJO; ERICK, 2015, p. 26). Além disso, segundo eles, também se observam a manutenção e a reiteração de privilégios e normatividades, mesmo em campos/pautas que se pretendem inovadoras e críticas. Ou seja, os temas predominantes são "quase sempre, (homo)sexualidade masculina, urbana, branca (ou negra urbana) e das regiões Sudeste ou Sul” (GONTIJO; ERICK, 2015, p. 27).

É válido ressaltar ainda que o presente dossiê nos permite questionar também o lugar de "periferização" ao qual as produções acadêmicas inscritas em universidades interioranas brasileiras foram relegadas, fazendo-se necessário "[indagar] sobre o porquê (e o como) desses 
desencaixes ou lacunas, ausências e possíveis silenciamentos" (GONTIJO, ERICK, 2015, p. $31)$.

Dentre os artigos selecionados para compor este dossiê, quatro deles são produções interioranas sobre tais contextos e respondem aos nossos questionamentos ao expressarem criatividade, dinamicidade e qualificada produção de conhecimento, contrapondo as compreensões subalternizantes que inscrevem as universidades "periféricas" como meras reprodutoras das teorias produzidas nos "centros", reiterando dessa forma uma "analítica da normalização" (GONTIJO; ERICK, 2015). Assim, se em um primeiro momento acreditávamos na existência de um Brasil profundo (e por que não Brasis?), os inúmeros trabalhos recebidos tanto daqui quanto do exterior apenas confirmam a riqueza e a pluralidade existentes e o quanto precisamos deslocar nossos olhares para esses outros horizontes de investigação, potencializando, inclusive, tal debate e produção na América Latina.

Se não basta a simples visibilidade de nossas pesquisas e de nossas produções para além de nossos "quintais" colonialmente produzidos, é necessário, principalmente, a produção de um conhecimento ética e politicamente comprometido com a evidenciação e com a denúncia das normatividades que atravessam e constituem também o mundo acadêmico e que são responsáveis pela criação e naturalização de clivagens assimétricas (DUQUE, OLIVEIRA, BECKER, 2020). E as Ciências Humanas e Sociais não estão isentas de serem atravessadas por essas lógicas.

Foi na tentativa, pois, de contribuir com essa ampliação do campo e deslocamento de um olhar autocentrado que, desde uma perspectiva transdisciplinar, aberta a diferentes campos e visões teórico-metodológicas, privilegiamos, na seleção, os artigos, pesquisas e reflexões que tivessem como foco ou se aproximassem da discussão de: formas de (homo)sociabilidade em contextos interioranos e/ou rurais; modos de discriminação e violências em relação às dissidências sexuais e/ou de gênero; sexualidades dissidentes e expressões de gênero na perspectiva dos marcadores sociais de diferença; trajetórias e narrativas dissidentes; estratégias de mobilização, negociação, agenciamento e resistência aos distintos regimes normativos; expressões de desejos, afetos e experimentações. 
Assim, em Pandemia, redes y sexualidades: una lectura crítica a los modos de (des)encuentro virtual, Paola Bonavitta (Universidad Nacional de Córdoba), Pascual Scarpino (Universidad Nacional de Córdoba) e Luciano Pascual (Universidad Nacional de Córdoba) buscam analisar as formas com que os usuários têm buscado se relacionar a partir da plataforma de sociabilidade "Grindr" depois que o governo argentino determinou o isolamento social, preventivo e obrigatório em decorrência da pandemia global de COVID-19.

Adriana Aguilar Flores (Instituto Nacional de las Mujeres - México) e Dalia Barrera Bassols (Escuela Nacional de Antropología e Historia - México), em Las otras 'nguiu' del Istmo de Tehuantepec - experiencias de campo, apresentam-nos uma reflexão sobre as vivências 'nguiu', em língua zapoteco, ou lésbicas, como algumas delas se autodenominam, em Oaxaca. As autoras debatem os enfrentamentos e acordos vividos por essas mulheres frente à alternativa de invisibilidade do desejo afetivo-sexual por outras mulheres.

No artigo Princesinha do norte por Babette: Identidades e homossociabilidades em Colatina nos anos 60, Randas Gabriel Aguiar Freitas (UFES), Luiz Cláudio Moisés Ribeiro (UFES) e Carlos Eugênio Soares de Lemos (UFF) analisam uma das sessões do jornal O Snob, produzida entre 1965 e 1968 no Rio de Janeiro. A partir disso, os autores nos apresentam as classificações identitárias e as formas de sociabilidade das dissidências de gênero e sexualidade na cidade de Colatina, no Espírito Santo, na década de 1960.

Por sua vez, os pesquisadores Alexsandro Rodrigues (UFES) e Steferson Zanoni Roseiro (UFES), no artigo Eu e a senhora sabemos o que é viver na roça, né, viado? Fogão a lenha, mach(ad)os e crianças, por meio da metáfora do "machado", discutem o dispositivo de cis/heteronormatização que incide violentamente sobre corpos dissidentes, de modo particular sobre infâncias dos interiores sertanejos deste grande país.

No artigo Tem lugar para as bichas? - Discurso acerca das sexualidades dissidentes e práticas heterotópicas, de autoria dos pesquisadores Samilo Takara (UNIR), Vinícius Colussi Bastos (UEL), a partir de uma análise qualitativa de um vídeo do Youtube, apresentamse as experiências de corpos e vidas dissidentes das normas de gênero e sexualidade que se inscrevem de diferentes modos nas localizações interior/capital. 
Já a pesquisadora Alice Alves Menezes Ponce de Leão Nonato (UFAM), no artigo Mulheres de velhices dissidentes e sexualidades transgressoras, brinda-nos com uma potente reflexão sobre gênero e envelhecimento na Amazônia. Sua pesquisa, desenvolvida junto a mulheres de Parintins-AM, ajuda-nos a compreender o papel transgressor da mulher idosa e suas articulações com o marcador regional.

No artigo Interações afetivo-sexuais entre mulheres e negociações com o contexto interiorano, Luis Felipe Rios do Nascimento (UFPE) e Luisa Mariana Vieira da Cruz (UFPE) investigam como as mulheres, em seus itinerários de lesbianidade, constroem estratégias de resistência à heterossexualidade compulsória nos espaços de sociabilidade do município de Serra Talhada/ PE, cidade natal de Lampião, marcada pelos resquícios machistas da cultura do cangaço.

Em Bissexualidade e pansexualidade: identidades monodissidentes no contexto interiorano do Rio Grande do Sul, as pesquisadoras Monalisa Dias de Siqueira (UFSM) e Danieli Klidzio (UFSM) propõem pensar as dissidências sexuais a partir da bissexualidade e pansexualidades vivenciadas por mulheres universitárias em contextos interioranos do Rio Grande de Sul. A investigação, questionadora da heterossexualidade compulsória, possibilita uma elucidação das experiências bissexuais e pansexuais ainda tão invisibilizadas socialmente.

Do mesmo modo, em Violência nas margens: prostituição, abjeção e trans-gressões, Paula Galrão (UNIVASF) e Paulo Dourian de Carvalho (UFRN) buscam compreender, através de uma pesquisa etnográfica, os processos de violência no cotidiano de travestis e transexuais diante da prostituição na cidade de Petrolina/PE.

Para finalizar, Neil Franco (UFJF) e Nayara Rios Cunha Salvador (UFJF), em Todo mundo tá sempre tomando conta da vida dos outros: vivências e trajetórias LGBTQIA+ em contextos interioranos, buscam refletir sobre os processos de constituição identitária, as vivências e trajetórias de quatro sujeitos que rompem com a cis/heteronormatividade em um contexto interiorano do estado do Rio de Janeiro.

Esperamos que a leitura dos artigos aqui apresentados possa servir de inspiração e estímulo a esta nova geração de pesquisadoras/es inquietas/os e comprometidas/os com a 
Revista

Debates Insubmissos

produção de conhecimentos descentrados e engajados com (d)enúncia e desestabilização das analíticas de normalização silenciadoras.

\section{REFERÊNCIAS}

DUQUE, Tiago; OLIVEIRA, Esmael Alves de; BECKER, Simone. Agência e

interseccionalidade em quadra: inquietações sobre escolas e diferenças em Mato Grosso do Sul. Revista Interritórios, v. 6, p. 225-242, 2020.

GONTIJO, Fabiano; ERICK, Igor. Diversidade sexual e de gênero, ruralidade, interioridade e etnicidade no Brasil: ausências, silenciamentos e... exortações. ACENO, vol. 2, n. 4, p. 24-40. ago/dez, 2015. 